\title{
Technical-economic justification of the choice of heat source autonomous heating schemes
}

\author{
Sergei Tikhomirov ${ }^{1, *}$, Gennadiy Golubov ${ }^{1}$, and Pavel Syichev ${ }^{1}$ \\ ${ }^{1}$ Don State Technical University, 344022 Sotsialisticheskaya 162, Russia
}

\begin{abstract}
One of the priority tasks of improving the fuel efficiency in the Russian Federation is the development of district heating systems. Such a policy spelled out in the Federal law "On heat supply" dated 27.07.2010 No. 190-FZ, the number of bylaws and regulations of the government. However, there is strong growth of low-rise, primarily residential construction in the country. Today major Russian cities are surrounded by settlements and gardening, where the laying of heat networks economically not justified. In the current environment are higher requirements for energy efficiency schemes for Autonomous heat supply heat sources to meet the seasonal and year-round loads, and also search of alternative ways of using the heat systems with heat pumps and solar systems. The paper discusses options for using in the circuits Autonomous heating such heat sources, like traditional and condensing hot water boilers. In this experiment you performed the study on the impact of modes of heating systems to customers in fuel efficiency. This is very important for technical applications results efficient operation of the systems of Autonomous heat supply.
\end{abstract}

\section{Introduction}

Optimization of heat supply systems was significant enough issue in the market of energy efficient sources of heat. Therefore, the wide application among all other find systems of Autonomous heating, which actively introduced in the last decade.

Currently, more acutely raises the question of energy efficiency. On this basis, the most urgent item of a larger program of optimization and modernization of the heat supply is the comparative characteristics of different systems of independent heat supply, the nominal power of which will show the advantages of one over the other on the basic commercial and operational indicators [1].

The aim of this work was to reduce energy consumption in the production of heat.

For solving the optimization problem of the scheme of Autonomous heat supply to reduce the operating cost was conducted research in a pilot plant consisting of a heating apparatus, low-temperature and conventional heating systems of the consumer, metering systems gas flow and the resulting thermal energy [2].

\section{Objectives of the research}

Efficient operation schemes of Autonomous heat supply requires fine tuning for each element. The main methods of fuel economy today are working to improve the efficiency of the heat source, which often serve as gas boilers [3]. If for a major boiler performance cards are prepared for all possible situations, the influence of heating domestic heating devices on their efficiency is considered to be insignificant [4]

The task of the pilot study was to test the influence of the thermal performance of traditional and condensing domestic boilers in the two typical modes by the value of their efficiency.

The object of the research was the current model schemes of heating system. The structure of the scheme included:

- a consumer of heat with variable load up to $30 \mathrm{~kW}$ consisting of a tank with cold tap water heat exchanger for heat recovery, fan coil unit, traditional high temperature heating system with radiators and floor heating circuit;

- the storage tank capacity of 500 liters to compensate for the daily non-uniformity of the heat load;

- piping system;

- a source of heat to cover the heat load of consumer;

- control of measured parameters [5], including flow meters and temperature sensors straight and return main boiler circuit, the heat accumulator and pump user groups. In addition to measuring consumption of heat was determined by the cost of fuel gas meters that are located at each boiler. The efficiency of boilers were determined as direct and reverse balance. For this purpose we used regular gas analyzer Testo 310.

\section{Methods of research and results}

To achieve this goal, we used the following methodology for conducting the experiments:

\footnotetext{
* Corresponding author: sergtihomirov@yandex.ru
} 
Before any work was performed visualization of all devices involved in the execution of skilled works. Checked the operation of the instrumentation system of metering the flow of gas and water piping, tightness of valves and faucets to ensure reliable and uninterrupted operation of the whole system.

Readings of gas consumption measured by meter stamps of Grand-3,2 (Gmax/Gmin=3,2/0,04 $\mathrm{m}^{3} / \mathrm{h}$ ), and heat consumption by heat energy meter type M-Cal MC1,5 (Gmax/Gmin=3,0 $\left.\mathrm{m}^{3} / \mathrm{h} 30 \quad \mathrm{l} / \mathrm{h}\right)$. The values recorded in the measurement Protocol.

In the works include each boiler, when it asked desired mode of operation of the heating system.

Before starting the boiler open the valves DN 15 on omitting, taps on the forward and return lines, piping, faucets hot and cold water boiler with the heated environment, the faucet to the consumer.

For both boilers typical modes of operation, in which the research was conducted was the temperature in the coolant supply/return lines $40 / 30{ }^{\circ} \mathrm{C}$ and $80 / 60{ }^{\circ} \mathrm{C}$. After achieving the required temperature at the outlet of the boiler in the measurement Protocol were made following testimonies: the temperature at the inlet and the outlet of the boiler, inlet and outlet from the consumer, the consumption of water before and after the boiler, power boiler and consumers. Every time after time was filmed readings of metering gas flow and heat meter.

In the technical theory of three-layer plates, the relationship between displacements and deformations has the form:

$$
\begin{gathered}
Q_{i}^{d} \cdot G=Q_{h s}+Q_{\text {loss }} \\
N \cdot \tau=\eta \cdot Q_{i}^{d} \cdot G
\end{gathered}
$$

where $Q_{d}^{i}$ - is the low heat of combustion, $\mathrm{kJ} / \mathrm{m}^{3}$;

$G$ - natural gas consumption, $\mathrm{m}^{3}$ /hour;

$Q_{h s}$ - heat, useful transferred to the heating system, kJ;

$Q_{\text {loss }}$ - heat loss, kJ;

$\eta$ - the efficiency of the heating apparatus;

$N$ - thermal capacity, $\mathrm{kW}$;

$\tau$ - the time experience, seconds.

Table 1. Test results of heating of the condensation boiler according to the temperature regime $40 / 30{ }^{\circ} \mathrm{C}$.

\begin{tabular}{|c|l|l|l|l|l|}
\hline № & $\begin{array}{c}\mathbf{G}, \\
\mathbf{m}^{\mathbf{3}} / \mathbf{h o u r}\end{array}$ & $\mathbf{t}_{\mathbf{1}},{ }^{\mathbf{0}} \mathbf{C}$ & $\mathbf{t}_{\mathbf{2}},{ }^{\mathbf{0}} \mathbf{C}$ & $\mathbf{N}, \mathbf{k W}$ & $\mathbf{\eta}$ \\
\hline 1 & 4,394 & 39,7 & 34,7 & 5,834 & 109,5 \\
\hline 2 & 4,441 & 39,9 & 34,9 & 5,889 & 107,8 \\
\hline 3 & 4,618 & 39,5 & 35,8 & 4,279 & 105,6 \\
\hline 4 & 4,689 & 39,5 & 35,9 & 4,215 & 104,7 \\
\hline 5 & 4,83 & 39,3 & 36 & 3,997 & 104,2 \\
\hline
\end{tabular}

Table 2. Test results of the heating boiler convection under temperature regime $40 / 30{ }^{\circ} \mathrm{C}$.

\begin{tabular}{|c|l|l|l|l|l|}
\hline № & $\begin{array}{c}\text { G } \\
\mathbf{m}^{\mathbf{3}} / \mathbf{h o u r}\end{array}$ & $\mathbf{t}_{\mathbf{1}},{ }^{\mathbf{0}} \mathbf{C}$ & $\mathbf{t}_{\mathbf{2}},{ }^{\mathbf{0}} \mathbf{C}$ & $\mathbf{N}, \mathbf{k W}$ & $\mathbf{\eta}$ \\
\hline 1 & 41,443 & 40 & 30,9 & 11,2 & 84,2 \\
\hline 2 & 41,684 & 41,3 & 34,5 & 8,4 & 86,5 \\
\hline 3 & 41,77 & 41,55 & 34,6 & 8,55 & 83,7 \\
\hline 4 & 41,871 & 41,9 & 35,1 & 8,4 & 82,4 \\
\hline 5 & 41,96 & 42,3 & 35,7 & 8,3 & 81,9 \\
\hline
\end{tabular}

Table 3. Test results of heating of the condensation boiler according to the temperature regime $80 / 60{ }^{\circ} \mathrm{C}$.

\begin{tabular}{|c|l|l|l|l|l|}
\hline $\mathbf{N o}$ & $\begin{array}{c}\mathbf{G}, \\
\mathbf{m}^{3} / \mathbf{h o u r}\end{array}$ & $\mathbf{t}_{\mathbf{1}},{ }^{\mathbf{0}} \mathbf{C}$ & $\mathbf{t}_{\mathbf{2}},{ }^{\mathbf{0}} \mathbf{C}$ & $\mathbf{N}, \mathbf{k W}$ & $\mathbf{\eta}$ \\
\hline 1 & 11,601 & 72,6 & 67,8 & 5,409 & 83,17 \\
\hline 2 & 11,676 & 67,7 & 66,3 & 1,64 & 80,43 \\
\hline 3 & 11,714 & 70,3 & 65,6 & 5,32 & 90,04 \\
\hline 4 & 11,766 & 69,5 & 64,7 & 5,343 & 85,28 \\
\hline 5 & 11,821 & 68,8 & 64,1 & 5,338 & 91,67 \\
\hline
\end{tabular}

Table 4. Test results of the heating boiler convection under temperature regime $80 / 60{ }^{\circ} \mathrm{C}$.

\begin{tabular}{|c|l|l|l|l|l|}
\hline № & $\begin{array}{c}\text { G, } \\
\mathbf{m}^{\mathbf{3}} / \mathbf{h o u r}\end{array}$ & $\mathbf{t}_{\mathbf{1}},{ }^{\mathbf{0}} \mathbf{C}$ & $\mathbf{t}_{\mathbf{2}},{ }^{\mathbf{0}} \mathbf{C}$ & $\mathbf{N}, \mathbf{k W}$ & $\mathbf{\eta}$ \\
\hline 1 & 57,823 & 80,4 & 65,9 & 16,1 & 80,9 \\
\hline 2 & 58,01 & 80,5 & 65,6 & 16,6 & 83,3 \\
\hline 3 & 58,185 & 80,6 & 68 & 15,66 & 85 \\
\hline 4 & 58,41 & 80,6 & 67,2 & 16,8 & 91,8 \\
\hline 5 & 58,77 & 81,1 & 63,7 & 21,6 & 90 \\
\hline
\end{tabular}

Testing domestic heating boilers, combination systems of Autonomous heating system of the building is made in accordance with the requirements of normative documents for direct measurement, using calibrated instruments and the error estimate. 
The pilot study revealed the dependence of the efficiency of household heating devices by the heat output at various modes of their work, the optimum conditions of a system of Autonomous heat supply in General, confirmed ways to reduce operating costs $[6,7]$.

\section{Evaluation of economic efficiency of the scheme Autonomous heating}

The economic viability of the various schemes of Autonomous heat supply is determined on the basis of the comparative economic efficiency of capital investments necessary to implement such actions, i.e. codeliver costs and the results obtained in these costs [8].

Cost is the most appropriate solution, which reduced the cost of $\Pi$, rub/year which are the sum of operating costs $C$ and capital investments $K$, reduced to the same dimension in accordance with the regulatory coefficient of comparative efficiency of capital investments $E_{n}$ :

$$
\Pi_{i}=C_{i}+E_{n} \cdot K_{i} \rightarrow \min
$$

where $i-$ the sequence number of variant design decisions.

The amount of the required capital investment $\mathrm{K}$, rub, determined by the formula:

$$
K=K_{r s}+K_{s m}+K_{p i}
$$

where $K_{r s}$ - cost design and estimate work, rub;

$K_{s m}$ - the cost of construction works (including commissioning works), rub;

$K_{p i}$ - the cost of a square of flooring that will host equipment systems, $\mathrm{rub} / \mathrm{m}^{2}$.

Given that the overhaul of the plant is performed not every year, you need the appropriate costs $P_{k i}$, rub/year to distribute by year using the following formula:

$$
P_{k i}=\frac{\left(C_{k i}+n_{\text {yeari }}\right)}{n_{\text {res }}}
$$

where $C_{k i}$ - the cost of one major repair, rub;

$n_{\text {yeari }}$ - annual fund operating time of the equipment or component of the device, h/year;

$n_{\text {res }}$ - resource time to the first major repair hours, the value of which for equipment operating under normal conditions.

Annual costs for maintenance and overhaul maintenance of equipment systems of autonomous heating system $P_{m i}$, rub/year, with the impending inflation is determined by the formula:

$$
\begin{aligned}
& P_{m i}=\sum_{T=1}^{T c c}\left(n_{c r} \cdot C_{c r} \cdot\left(\frac{n_{g a s}}{n_{r e s}}\right)+C_{s m}+\right. \\
& \left.n_{c e} \cdot C_{c e} \cdot n_{i} \cdot C_{i} \cdot \frac{n_{g a s}}{n_{r e s}}\right) \cdot \frac{\left(1+\gamma_{s n}\right)^{T}}{T_{c r}}
\end{aligned}
$$

where $n_{c r}$ - number of current repairs in the period between two overhauls the previous and following him;

$C_{c r}$ - the cost of one repair in the current year, the start of the heating system, rub;

$C_{s m}$ - annual costs for system maintenance for the first year of its validity, rub;

$n_{c e}$ - number of cleanings of the equipment per year;

$C_{c e}$ - cost of one cleaning the equipment in the same year of the system, rub/hour;

$n_{i}$ - number of inspections of the installation in the period between two overhauls;

$C_{i}$ - the cost of one examination in the same year, $\mathrm{rub} /$ insp.

Energy costs $E$ consumed by the pumps of systems of heating, ventilation, air conditioning and automation of these systems are determined by formula, not taking into account the coming inflation of energy prices:

$$
\begin{aligned}
& E=\left(\sum_{n=1}^{n^{\prime \prime}} W_{e}^{n} \cdot n_{h}^{n} \cdot n_{\text {day }}^{n}+\right. \\
& \left.\sum_{q=1}^{q^{\prime}} W_{e}^{q} \cdot n_{h}^{q} \cdot n_{\text {day }}^{q}\right) \cdot C_{e}
\end{aligned}
$$

where $W_{e}^{n}, W_{e}^{q}$ - estimated costs of electricity, respectively, by the pumps of the heating system and automation equipment, $\mathrm{kW}$;

$n_{d a y}^{n}, n_{d a y}^{q}$ - duration of the operation of this equipment, hours/day;

$n_{h}^{n}, n_{h}^{q}$ - the same day/year.

$n^{\prime \prime}, q^{\prime}$ - the number of pumps and automation panels

$C_{e}$ - electricity at two betting rate, $(\mathrm{rub} / \mathrm{kW} \cdot \mathrm{h})$.

The cost of gas, rub/year, occurring prior to the installation of equipment, can be subject to price increase for the overspent part determined by the formula:

$$
\sum T_{n i}=T_{n i}+T_{n i}^{\partial o n}+2 \Delta T_{n}
$$

where 2-additional fee for excessive part, in shares from $\Delta T_{n}$;

$\Delta T_{n}$. - payment for the specified part of the gas, rub/year, determined in accordance with the meter readings.

The work was carried out economic assessment and comparison of schemes autonomous heating with different heat sources (conventional and condensing boilers). 
Table 5. Comparative characteristics of the condensing and traditional hot water boilers in the traditional scheme of an autonomous heating without solar collector and heat pump.

\begin{tabular}{|l|l|l|}
\hline The type of boiler & Convection & Condensation \\
\hline The cost of design work, rub & 30000 & 30000 \\
\hline $\begin{array}{l}\text { The cost of construction and } \\
\text { installation, rub }\end{array}$ & 100000 & 100000 \\
\hline $\begin{array}{l}\text { The cost of a square of } \\
\text { flooring, rub }\end{array}$ & 40000 & 40000 \\
\hline The cost of the equipment, rub & 73000 & 91000 \\
\hline Capital investments, rub & $\mathbf{2 4 3 0 0 0}$ & $\mathbf{2 6 1 0 0 0}$ \\
\hline The cost of gas, rub/year & 31332 & 26733 \\
\hline Electricity costs, rub/year & 3275 & 3275 \\
\hline $\begin{array}{l}\text { The cost of overhaul and } \\
\text { repair, rub/year }\end{array}$ & 4301 & 5001 \\
\hline $\begin{array}{l}\text { Operating cost, rub/year } \\
\text { Operating costs and } \\
\text { depreciation of equipment, } \\
\text { rub/year }\end{array}$ & $\mathbf{5 1 0 5 8}$ & $\mathbf{3 8 9 0 8}$ \\
\hline
\end{tabular}

Table 6. Comparative characteristics of the condensing and traditional hot water boilers in the combined scheme of an autonomous heating with boiler and solar collector.

\begin{tabular}{|c|c|c|}
\hline The type of boiler & Convection & Condensation \\
\hline The cost of design, rub & 30000 & 30000 \\
\hline $\begin{array}{l}\text { The cost of construction and } \\
\text { installation, rub }\end{array}$ & 400000 & 400000 \\
\hline $\begin{array}{l}\text { The cost of a square of } \\
\text { flooring, rub }\end{array}$ & 70000 & 70000 \\
\hline The cost of the equipment, rub & 273000 & 291000 \\
\hline Capital investments, rub & 773000 & 791000 \\
\hline The cost of gas, rub/year & 27723 & 23654 \\
\hline Electricity costs, rub/year & 9407 & 9407 \\
\hline $\begin{array}{l}\text { The cost of overhaul and } \\
\text { repair, rub/year }\end{array}$ & 4301 & 5002 \\
\hline Operating cost, rub/year & 41431 & 38063 \\
\hline $\begin{array}{l}\text { Operating costs and } \\
\text { depreciation of equipment, } \\
\text { rub/year }\end{array}$ & 80081 & 77613 \\
\hline
\end{tabular}

Table 7. Comparative characteristics of the condensing and traditional hot water boilers in the combined scheme of an autonomous heating with boiler, solar collector and heat pump.

\begin{tabular}{|l|l|l|}
\hline The type of boiler & Convection & Condensation \\
\hline The cost of design, rub & 30000 & 30000 \\
\hline $\begin{array}{l}\text { The cost of construction } \\
\text { and installation, rub }\end{array}$ & 400000 & 400000 \\
\hline $\begin{array}{l}\text { The cost of a square of } \\
\text { flooring, rub }\end{array}$ & 100000 & 100000 \\
\hline $\begin{array}{l}\text { The cost of the } \\
\text { equipment, rub }\end{array}$ & 723000 & 741000 \\
\hline $\begin{array}{l}\text { Capital investments, } \\
\text { rub }\end{array}$ & $\mathbf{1 2 5 3 0 0 0}$ & $\mathbf{1 2 7 1 0 0 0}$ \\
\hline The cost of gas, rub/year & 9986 & 8520 \\
\hline Electricity costs, & 30323 & 30323 \\
\hline
\end{tabular}

\begin{tabular}{|l|l|l|}
\hline rub/year & & \\
\hline $\begin{array}{l}\text { The cost of overhaul and } \\
\text { repair, rub/year }\end{array}$ & 14496 & 15197 \\
\hline $\begin{array}{l}\text { Operating cost, } \\
\text { rub/year }\end{array}$ & $\mathbf{5 4 8 0 5}$ & $\mathbf{5 4 0 4 0}$ \\
\hline $\begin{array}{l}\text { Operating costs and } \\
\text { depreciation of } \\
\text { equipment, rub/year }\end{array}$ & $\mathbf{1 1 7 4 5 5}$ & $\mathbf{1 1 7 5 9 0}$ \\
\hline
\end{tabular}

\section{Conclusions}

The study of developments in the field of condensing and traditional heating technology of Autonomous systems of heating, allowed to systematize the data and to justify the direction and objectives of the study.

The developed model feasibility study selection of the heat source Autonomous heating schemes, allowing to analyze the features of reducing operational costs in the annual cycle depending on the set-up and thermalhydraulic regimes of its work.

The factors to assess the impact, modal and thermophysical parameters on the determination of the efficiency of the combined scheme of an Autonomous heating with multiple heat sources.

Designed experimental stand, methodology and testing program condensing and traditional boilers, which allows to determine the dependence of the efficiency of the heat source from the thermal-hydraulic and climatic factors.

A study of the impact on efficiency of the heat generator combined circuit Autonomous heating, operating conditions and climatic factors.

\section{References}

1. P.A. Khavanov, ABOK, 1, 34 (2004)

2. S.A.Tikhomirov, O.K. Mazurova, P. A. Syichev, Construction and Architecture - 2015, 1, 191-192 (2015)

3. P.A. Khavanov, Vestnik MGSU, 7, 429-435 (2011)

4. S.G. Sheina, S.A. Tikhomirov, E.N. Minenko, International Journal of Applied Engineering Research, 10 (12), 31389-31402 (2015)

5. S.A.Tikhomirov, V.G. Fedorovsky, P.V. Stasenko, Construction - 2015, 1, 229 (2015)

6. O.E. Rakhnov, I.Y. Saklakov, A.D. Potapov, Vestnik MGSU, 11, 177-187 (2013)

7. P.A. Khavanov, E.B. Solovyova, Scientific review, 4, 128-130 (2013)

8. A.I. Eremkin, T.I. Koroleva, G.V. Danilin, V.V. Byzev, A.G. Averkin, The economy of energy conservation in heating, ventilation and airconditioning, (2008) 